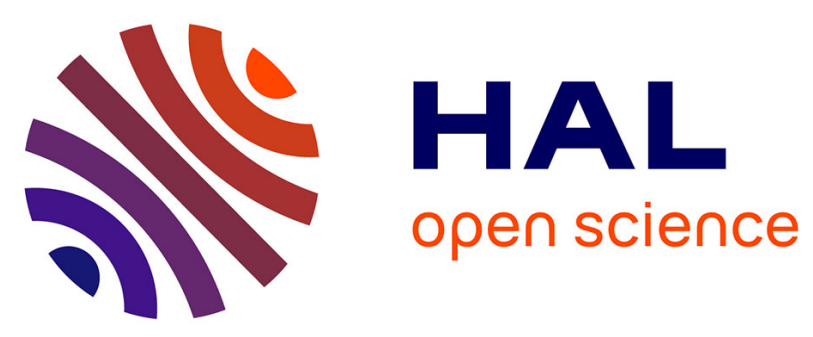

\title{
Demonstrating the contribution of dielectric permittivity to the in-phase EMI response of soils: example of an archaeological site in Bahrain
} Christophe Benech, Pierre Lombard, Fayçal Rejiba, Alain Tabbagh

\section{- To cite this version:}

Christophe Benech, Pierre Lombard, Fayçal Rejiba, Alain Tabbagh. Demonstrating the contribution of dielectric permittivity to the in-phase EMI response of soils: example of an archaeological site

in Bahrain. Near Surface Geophysics, 2016, 14 (4), pp.337-344. 10.3997/1873-0604.2016023 . hal01376230

\author{
HAL Id: hal-01376230 \\ https://hal.sorbonne-universite.fr/hal-01376230
}

Submitted on 4 Oct 2016

HAL is a multi-disciplinary open access archive for the deposit and dissemination of scientific research documents, whether they are published or not. The documents may come from teaching and research institutions in France or abroad, or from public or private research centers.
L'archive ouverte pluridisciplinaire HAL, est destinée au dépôt et à la diffusion de documents scientifiques de niveau recherche, publiés ou non, émanant des établissements d'enseignement et de recherche français ou étrangers, des laboratoires publics ou privés. 
1 Demonstrating the contribution of dielectric permittivity to the in-phase EMI response

4 Christophe Benech ${ }^{1}$, Pierre Lombard ${ }^{1}$, Fayçal Rejiba ${ }^{2}$, Alain Tabbagh ${ }^{2}$

${ }^{1}$ UMR 5133 Archéorient, Maison de l'Orient et de la Méditerranée - Université Lyon 2

${ }^{2}$ Sorbonne Universités, UPMC Paris6, UMR7619, Métis, F-75252 Paris

(

(

\section{Abstract} lower frequencies and theoretical models reported in the literature.

\section{of soils: example of an archaeological site in Bahrain.}

Electromagnetic Induction, EMI, instruments (also called loop-loop, dipole-dipole or Slingram) are now commonly used for archaeological prospection. They are truly light instruments, which are able to measure both the apparent electrical conductivity and the apparent magnetic susceptibility of the ground. During a field test on Bahrain Island, where the soil has a high clay content and a high salt content, surprisingly high values of in-phase response were obtained at all inter-coil spacings, using the CMD 'mini-explorer' (GF instrument Ltd, Brno) at $30 \mathrm{kHz}$, in both HCP and VCP configurations and the HCP and VCP susceptibility variations were in total opposition. This apparent discrepancy is explained by considering the in-phase responses to be dominated by the relative dielectric permittivity. Using the raw, in-phase, VCP and HCP data, it is possible to determine and map the apparent permittivity and apparent magnetic susceptibility. For this case of slated soils with high clay content the relative permittivity is strong, but in agreement with both experimental data at 
Key-words: Electromagnetic induction measurements, low induction number, relative permittivity mapping of soil, magnetic susceptibility mapping of soil

\section{Introduction}

The island of Bahrain, located in the Arabian/Persian Gulf on the tropic of Cancer, has been occupied by humans for a long time. It is well known for its important necropolises dating from the Dilmun civilization (Bronze Age) until the Hellenistic period. The burial mounds are so numerous that until the 20th century, Bahrain was often referred to as "Necropolis Island" with no permanent settlement. Archaeologists finally proved that a brilliant and original civilization had prospered on this island, during the Dilmun period in particular. This civilization played an important role as the crossroads for commercial traffic in the Gulf (Bibby 1972, Crawford 1998, Lombard 1999), facilitating the trade of metals between Oman and Mesopotamia in particular.

Within the framework of the French archaeological mission, a set of geophysical tests has been carried out at different sites on the island since 2011 , in order to evaluate the most relevant methods for various types of archaeological and environmental exploration. The site of primary interest is that of Qal'at al-Bahrain, located on the island's north coast. This site is a 17 ha 'tell', which was almost continuously occupied from the second half of the third millennium BC until the 17th century AD. Although part of the site is now dominated by a Portuguese fort built in the 16th century, excavations carried out since 1954 by a Danish team from the Aarhus University led by Peter Vilhelm Glob have revealed a major settlement from the Dilmun period, including a 'settlers' palace from Kassite Babylonia (15th c. B.C.), with cuneiform archives (Glob 1968). The continuous stratigraphy is also a fundamental reference 
for the history of the island, of which Qal'at al-Bahrain was a major settlement, and probably the capital during the Dilmun period.

The soil is very clayey, and has developed over a marl weathered substratum, the prevailing arid climate and proximity of the sea promoting the accumulation of salt. Due to its high clay and salt contents, the ground's electrical resistivity is often lower than $10 \Omega \mathrm{m}$, which precludes the use of ground penetrating radars (GPR). Although very high responses to conductivity-meters can also be expected (Frohlich and Lancaster 1986), there is no reason to expect particularly strong magnetic properties. However, over most of the surveyed areas surprisingly high results were obtained for the in-phase component of signals recorded by the EMI instrument.

The aim of the present study is thus to develop an explanation for the in-phase EMI results recorded at this site. We focus on a limited $40 \times 40 \mathrm{~m}^{2}$ surface area, surveyed at the Qal'at al Bahrain Dilmun settlement site, where magnetic and low EMI induction number prospections were carried out, using the CMD 'mini-explorer' (Gf Instrument Ltd, Brno) in both HCP (horizontal coplanar) and VCP (vertical coplanar) configurations.

\section{Constraints deduced from the magnetic survey}

The surface area under consideration is part of the area surveyed in 2011 , using the G858 (Geometrics Ltd) total field cesium magnetometer with two sensors, the upper sensor being positioned at a height of $1.03 \mathrm{~m}$ and the lower sensor at $0.4 \mathrm{~m}$, this configuration allows measurement either in vertical gradient of the magnetic field intensity mode or simply of this intensity at each height. The inter-profile distance was $1 \mathrm{~m}$ and the finally restored mesh was $0.5 \times 0.5 \mathrm{~m}^{2}$. Most of the archaeological remains revealed by the magnetic map appear to belong to the late occupation of the site, probably to the medieval period (Fig. 1). In the NE corner of the map, the gradient clearly shows what can be interpreted as the continuation of 
the Dilmun fortification. Along the southern side of the fortification, and parallel to this, one can see a rectangular, $20 \times 35 \mathrm{~m}$ building. A $5 \mathrm{~m}$ wide path is also visible, between this building and the fortification. Although it is difficult to provide a more accurate description of the internal organization of the building, its location and orientation suggest that it may also belong to the Dilmun period.

On this site, the inclination of the Earth's magnetic field is $40^{\circ}$ and its modulus is approximately $43800 \mathrm{nT}$. With the exception of a small number of iron objects disseminated over the path crossing the site, the vertical gradient lies in the range between -2 and $+5 \mathrm{nT} / \mathrm{m}$. Magnetic prospecting is one of 'potential' methods, the average magnitude of the field bears no relationship to the magnetic properties of the soil and depends on the location of the survey at the earth surface; lateral variations only can reveal characteristics of the underground structure and be used for comparison with other prospection methods.

If the gradient (or the field intensity at one level) variations are converted into vertical magnetization variations of a magnetized layer (Desvignes et al. 1999), centered at a depth of $0.25 \mathrm{~m}$ and a thickness of $0.5 \mathrm{~m}$, an interquartile distance of $21110^{-5} \mathrm{SI}$ is obtained for the equivalent susceptibility. This value is quite high, but also includes the viscous magnetization which, for 4000 years (Mullins 1974, Pétronille et al. 2010), was equivalent in magnitude to the induced magnetization. The order of magnitude of the susceptibility's interquartile distance can thus be estimated at around $10010^{-5} \mathrm{SI}$.

\section{CMD ‘mini-Explorer’ results}

The CMD is a multi-receiver EMI (Electro-Magnetic Induction) slingram instrument. It comprises one transmitter coil and three receiver coils, located at $0.32,0.71$ and $1.18 \mathrm{~m}$ from the transmitter. All the coils are coplanar, allowing the instrument to be used in either the HCP or the VCP configuration. The instrument's operating frequency is $30 \mathrm{kHz}$, and in the 
field it can be used in a continuous recording mode by a mobile operator. At the different sites in Bahrain, this mode was used with a $0.1 \mathrm{~s}$ recording interval, with the coil centers having a clearance above the ground of $h=0.12 \mathrm{~m}$. In the following descriptions, we consider the results obtained for both VCP and HCP configurations, using the $0.71 \mathrm{~m}$ and $1.18 \mathrm{~m}$ inter-coil separations only.

The manufacturer chose to express the $\mathrm{Hs} / \mathrm{Hp}$ in-phase measurements in ppt (part per thousand) with two decimals digits and with a change of sign. For the quadrature out-of-phase component, the $\mathrm{Hs} / \mathrm{Hp}$ ratio is multiplied by $-\frac{4}{\mu_{0} \omega L^{2}}$ (where $L$ is the inter-coil distance, $\omega$ the angular frequency, and $\mu_{0}$ the magnetic permeability in vacuum) such that in the case of media having a moderate conductivity, the displayed value corresponds to the apparent conductivity when $h=0$. To respect the standard definition of any apparent property (the physical property of a homogeneous ground giving the same response with the same instrument configuration in the same measuring conditions), prospector must retranslate this value into the quadrature of the field ratio, and then apply the general formulas (Thiesson et al. 2014) which take into account the non-linearity of the conductivity response, as well as the clearance above the surface, when computing the apparent conductivity at each point. The four apparent conductivity maps obtained for the HCP and VCP configurations and the $0.71 \mathrm{~m}$ and $1.18 \mathrm{~m}$ inter-coil distances are shown in Fig. 2. These are coherent, since the slight increase in resistivity between the VCP and HCP configurations, and between the measurements obtained at separations of $0.71 \mathrm{~m}$ and $1.18 \mathrm{~m}$, can be explained simply by a decrease in conductivity as a function of depth. The variations in resistivity are clearly different to those of the magnetic properties revealed by the magnetic map.

In the context of highly conductive soil, part of the in-phase response is generated by its conductivity. In order to correct for this effect, one has computed, at each point of the survey, the in-phase response corresponding to the apparent conductivity determined from the 
quadrature response. After subtracting this part, the remaining in-phase signal is usually considered to have been generated by the soil's magnetic susceptibility (Scollar et al. 1990, Farquharson et al. 2003, Bonsall et al. 2013, De Smedt et al. 2014). The response to soil's susceptibility is linear and the corresponding coefficients are provided in the second column of Table 1 (at frequency $f=30 \mathrm{kHz}$, and height $h=0.12 \mathrm{~m}$ ). The slopes given in this table can be seen to depend on the distance between the coils, and to be positive for the VCP, and negative for the HCP configurations, this opposite variation has been verified by observing the in-phase variation with $h$ over low conductivity grounds.

The four maps of the in-phase ratios corrected from the conductivity responses are presented in Fig. 3 with the corresponding magnetic susceptibility scales; it should be noted that in the case of in-phase responses resulting from mechanical deformations (mainly thermal drift) of the instrument's structure, the uncertainty remains close to the exact value of zero, even when regular checks are carried out by raising the instrument (Thiesson et al. 2014). A totally unexpected outcome, contrary to all of the results previously acquired with this instrument and other EMI sensors, is revealed in this figure: the variations in magnetic susceptibility in the VCP and HCP configurations are in total opposition, i.e. the VCP minima correspond to HCP maxima, and vice versa.

Two complementary remarks can be made:

1) The global variability, expressed by the standard deviation in magnetic susceptibility is greater at a coil separation of $1.18 \mathrm{~m}$ than at $0.71 \mathrm{~m}\left(4710^{-5} \mathrm{SI}\right.$ in $\mathrm{HCP}$ at $1.18 \mathrm{~m}, 4010^{-5} \mathrm{SI}$ in $\mathrm{HCP}$ at $0.71 \mathrm{~m}, 7010^{-5} \mathrm{SI}$ in $\mathrm{VCP}$ at $1.18 \mathrm{~m}$ and $2010^{-5} \mathrm{SI}$ in $\mathrm{VCP}$ at $0.71 \mathrm{~m}$ ), and this effect is more pronounced in VCP than in HCP.

2) These results are strongly correlated with the resistivity map. How can this outcome be explained? 


\section{The role of the dielectric permittivity}

Following a series of verifications, we came to the conclusion that the in-phase responses obtained with the $\mathrm{CMD}$ at Bahrain were influenced by the instrument's response to dielectric permittivity, rather than its response to magnetic susceptibility.

In general, with EM measurements, the electrical properties intervene in the MaxwellAmpère equation via (in the frequency domain) a complex expression $(\sigma+i \omega \varepsilon)$, in which the conductivity, $\sigma$, corresponds to the macroscopic electric charge motion, whereas the permittivity, $\varepsilon$, corresponds to the macroscopic electric polarization, i.e. the non-coincidence between the barycenter of positive electric charges and the barycenter of negative electric charges. Although at low frequencies one can write $\sigma>>\varepsilon \omega$ (which does not mean that the influence of $\varepsilon$ is negligible when compared to that of the magnetic susceptibility), when the conductivity is low the polarization is usually taken into account even in the low frequency range (Huang and Fraser 2001, Hodges 2004).

To assess the physical meaning of the polarization response in EMI instruments on can consider the analogous of the induction number where $(\sigma+i \omega \varepsilon)$ replaces $\sigma$. It can be then deduced that the response, there approximately proportional to $i \mu_{0} \omega(\sigma+i \omega \varepsilon) L^{2}$, will increase as $L^{2}$ and the permittivity response will be in phase and proportional to $\omega^{2}$. The in-phase response will thus be 9 times more sensitive to the permittivity at $30 \mathrm{kHz}$ than at $10 \mathrm{kHz}$, and 2.8 times more sensitive at an inter-coil spacing of $1.18 \mathrm{~m}$ than at $0.71 \mathrm{~m}$.

Using the complete EM calculation (Thiesson et al. 2014), Fig. 4 shows the plots of the in-phase response as a function of magnetic susceptibility and dielectric permittivity, for VCP, HCP, and different values of coil spacing. These results were computed using the characteristics of the CMD when operated above a homogeneous ground (conductivity $=0.1$ $\mathrm{Sm}^{-1}$ in all cases, magnetic susceptibility $\kappa_{\mathrm{ph}}=5010^{-5} \mathrm{SI}$ in the case of variable permittivity, and relative permittivity $\varepsilon_{\mathrm{r}}=1000$ in the case of variable susceptibility). All the responses are 
linear, and the magnetic susceptibility and relative permittivity responses are strictly additive.

The slopes of the permittivity responses increase when the spacing is increased from $0.71 \mathrm{~m}$ to $1.18 \mathrm{~m}$. The major result of this analysis is that, whereas all the slopes have the same sign in VCP, the slopes of the permittivity and susceptibility responses are of opposite sign in HCP. Thus, if the in-phase response is (incorrectly) considered to be generated by the susceptibility, whereas it is in fact dominated by the permittivity, this can lead to a change in sign of the computed HCP susceptibility. This gives a perfect explanation for the apparent contradiction observed at the Bahrain Island site, and provides evidence of the dominant influence of the soil's permittivity when compared to that of its susceptibility.

The slope of both properties ( $\alpha$ for the slope of the susceptibility, and $\beta$ for the slope of the permittivity) are provided in Table 1. It can be seen that, although the instrument's sensitivity to a change of 1 in relative permittivity is much weaker than its sensitivity to a change of $110^{-5} \mathrm{SI}$ in susceptibility, its permittivity response can become greater than its susceptibility response when the permittivity reaches high values, i.e. 1000 or more. Are such high values likely to occur in soils in this frequency range? Yes, due to the Maxwell-Wagner polarization, membrane polarization and Stern layer polarization effects when the soil contains a sufficiently high proportion of clay platelets and ions (Börner et al. 1993, Cosenza et al. 2008, Tabbagh et al. 2009, Kessouri 2012, Kemna et al. 2012, Revil 2013, Okay et al. 2014, Weller et al. 2015). This is clearly the case in Bahrain. The in-phase measurements must therefore be interpreted as the algebraic sum of the susceptibility and permittivity responses, with the latter having a significantly greater magnitude.

\section{Determination of both susceptibility and permittivity}

Is it possible to separate the responses of these two properties? Several approaches can be considered: (i) the use of several different frequencies, since, to a first approximation, the 
permittivity response is proportional to the square of the frequency, whereas that of the susceptibility is comparatively independent on frequency, (ii) the use of both HCP and VCP measurements, acquired at each survey point, and (iii) the comparison of responses measured at different inter-coil spacings. The first solution cannot be applied with the CMD instrument, since it operates at one fixed frequency, and the third solution is confronted with the very complex problem of untangling the respective variations in susceptibility and permittivity as a function of depth. In practice, this can be solved only through the use of a full inversion process. However, the second approach can be applied in the present context.

As the in-phase response dependences on these parameters are linear, a solution is required for the following system of two equations:

$P h(H s / H p)_{V C P}=\operatorname{Zero}_{V C P}+\alpha_{V C P} K p h+\beta_{V C P} \varepsilon_{r}$ $P h(H s / H p)_{H C P}=$ Zero $_{H C P}+\alpha_{H C P} K p h+\beta_{H C P} \varepsilon_{r}$

As already noted above, as a consequence of the slight mechanical instability of the instrument's structure, it is difficult to accurately fix the in-phase zero offset. We thus assume that the zero is the same for both coil configurations, and has a value that minimizes the average cross-product between the HCP and VCP in-phase measurements. It is important to note that the uncertainty in this zero value does not affect the magnitude of the variations in the apparent property strengths.

The resulting susceptibility and permittivity maps are presented in Fig. 5. The computed standard deviation of the permittivity is 4850 at $L=0.71 \mathrm{~m}$, and 4450 at $L=1.18 \mathrm{~m}$. The maps can be seen to be very similar, and well correlated with the resistivity maps (Fig. 2). The computed standard deviation of the susceptibility is $2510^{-5} \mathrm{SI}$ at $L=0.71 \mathrm{~m}$ and $6310^{-5} \mathrm{SI}$ at $L=1.18 \mathrm{~m}$. The variations in susceptibility can be seen to be considerably weaker in the case of the shorter coil spacing. As the instrument response is dominated by variations in the 
ground's permittivity, it is not surprising that the two susceptibility maps (at $L=0.71$ and $1.18 \mathrm{~m}$ ) appear to be less coherent.

\section{Conclusions and perspectives}

EMI measurements carried out using the CMD 'mini-Explorer' on Bahrain Island must be interpreted within their specific context: a clayey soil close to the sea, in an arid climate. When interpreting these data, it is important to remember that the soil's properties, both magnetic and electrical, can affect the EM measurements. However, as the high permittivity of a salt-laden, clayey soil is also associated with a very high conductivity, the prospector should be aware of the risk of the in-phase response being dominated by the soil's permittivity, rather than by its magnetic susceptibility. This tendency becomes stronger when higher frequencies or coil separations are used.

With EMI, as with other geophysical techniques, it is always possible to directly invert the raw data through the use of a complete inversion process, without prior transformation of the data into apparent property maps. This step is however very important, because it can have a major influence on the entire interpretation process. In the case of EMI prospection, spatial variations in permittivity correspond to variations in the soil's characteristics, such as clay content, clay type, ionic force, pore size, whereas fluctuations in magnetic susceptibility are indicative of variations in the oxido-reduction conditions occurring during pedogenesis, and resulting from human occupation.

The combined use of EMI measurements, obtained with different instrumental 244 configurations, was determinant in the interpretation of data recorded over the soil on Bahrain Island. This type of combined measurement, using different coil configurations, represents a highly interesting approach. In the future, this may allow one of the objectives of EM 247 prospection to be achieved: the simultaneous measurement of electrical conductivity, 
dielectric permittivity, magnetic susceptibility and magnetic viscosity, at different depths of investigation.

\section{Acknowledgements}

The authors extend their sincere thanks to the French archaeological mission to Bahrain, which provided fruitful collaboration and funding for this project. They also wish to thank the Directorate of Archaeology and Heritage, and the Ministry of Culture of the Kingdom of Bahrain, for their financial support and assistance in the organization of the geophysical campaigns.

\section{References}

Bibby T.G. 1972. Looking for Dilmun. Pelican Series, Penguin Books, Harmondsworth.

Bonsall J., Fry R., Gaffney C., Armit I., Beck A., Gaffney V., 2013. Assessment of the CMD Mini-Explorer, a new low-frequency multi-coil electromagnetic device for archaeological investigations. Archaeological Prospection, 20, 219-231.

Börner F., Gruhne M., Schön J., 1993. Contamination indications derived from electrical properties in the low frequency range. Geophysical Prospecting, 41, 83-98.

Cosenza P., Ghorbani A., Revil A., Zamora M., Schumtz M. Jougnot D., Florsch N., 2008, A physical model of the low-frequency electrical polarization of caly rocks. Journal of Geophysical Research, 113, B08204.

Crawford H. 1998. Dilmun and its Gulf neighbours. Cambridge: Cambridge University Press

De Smedt P., Saey T., Meerschman E., De Reu J., De Clercq W., van Meirvenne M., 2014. Comparing apparent magnetic susceptibility measurements of a multi-receiver EMI sensor with topsoil and profile magnetic susceptibility data over weak magnetic anomalies. Archaeological Prospection, 21, 103-112. 
273 Desvignes G., Tabbagh A. \& Benech C., 1999. About the determination of magnetic anomaly 274 sources. Archaeological Prospection, 6, 85-105.

275 Farquharson C. G., Oldenburg D. W., Routh P. S., 2003. Simultaneous 1D inversion of loop276 loop electromagnetic data for magnetic susceptibility and electrical conductivity. Geophysics, $277 \quad 68,1857-1869$.

278 Frohlich B., Lancaster W. J., 1986. Electromagnetic surveying in current Middle Eastern 279 archaeology: application and evaluation. Geophysics, 51, 1414-1425.

280 Glob P. V., 1968. Al-Bahrain: De danske ekspeditioner til oldtidens Dilmun, Klicheer: 281 Kondrup \& Rasmussen.

282 Hodges G., 2004. Mapping conductivity, magnetic susceptibility, and dielectric permittivity 283 with helicopter electromagnetic data. $74^{\text {th }}$ annual Meeting SEG, Denver-USA, 10-15 october 2842004.

285 Huang H. and Fraser D. C., 2001. Mapping of the resistivity, susceptibility and permittivity of 286 the earth using a helicopter-borne electromagnetic system. Geophysics, 66, 148-157.

287 Lombard P. (éd.) 1999. Bahreïn. La civilisation des Deux Mers, de Dilmoun à Tylos. 288 Catalogue de l'exposition organisée à l'Institut du Monde Arabe (Paris), du 18 mai au 29 août 289 1999, Institut du Monde Arabe \& Éditions SNZ, Paris et Gand.

290 Mullins C. E., 1974, The magnetic properties of the soil and their application to 291 archaeological prospecting. Archaeo-Physika, 5, 133-347.

292 Kemna A., Binley A., Cassiani G., Niederleithinger E., Revil A., Slater L. Williams K. H., 293 Flores Orozco A., Haegel F.-H., Hördt A., Kruschwitz S., Leroux V., Titov K., Zimmermann 294 E., 2012. An overview of the spectral induced polarization method for near surface 295 applications. Nera Surface Geophysics, 10, 453-468. 
Kessouri P., 2012. Mesure simultanée aux fréquences moyennes et cartographie de la

297

298

299

300

301

302

303

304

305

306

307

308

309

310

311

312

313

314

315

316

317

permittivité diélectrique et de la conductivité électrique du sol. PhD thesis Université Pierre et Marie Curie, 230p.

Okay G., Leroy P., Ghorbani A., Cosenza P., Camerlynck C., Cabrera J., Florsch N., Revil A., 2014. Spectral induced polarization of clay-sand mixtures: Experiments and modeling. Geophysics, 79-6, E353-E375.

Pétronille M., Thiesson J., Simon F.-X., Buchsenschutz O., 2010. Magnetic signal prospecting using multiparameter measurements: the case study of the gallic site of Levroux. Archaeological Prospection, 17, 141-150.

Revil A., 2013. Effective conductivity and permittivity of unsaturated porous materials in the frequency range $1 \mathrm{mHz}-1 \mathrm{GHz}$. Water Resources Research, 49, 306-327.

Scollar I., Tabbagh A., Hesse A., Herzog I., 1990. Archaeological Prospecting and Remote Sensing. Cambridge University Press.

Tabbagh A., Cosenza P., Ghorbani A., Guérin R., Florsch N., 2009. Modelling MaxwellWagner induced polarization amplitude for clayed material. Journal of Applied Geophysics, 67, 109-113.

Thiesson J., Kessouri P., Schamper C., Tabbagh A., 2014. Calibration of frequency-domain electromagnetic devices used in near-surface surveying. Near Surface Geophysics, 12, 481491.

Weller A., Slater L., Huisman J. A., Esser O., Haegel F.-H., 2015. On the specific polarizability of sands and sand-clay mixtures. Geophysics, 80, A57-A61. 


\section{Figure captions}

319 Figure 1: Qal'at - al- Bahrain site, a) general view and locations of the Portuguese fort, of the

320 Hellenistic fortress, of the magnetic vertical gradient map and contour of the $40 \mathrm{x} 40 \mathrm{~m}^{2}$ E.M.

321 test area, b) detail map of the vertical gradient of the total field with proposed interpretation in

322 link with the Dilmun period.

323 Figure 2: Apparent resistivity measured with the CMD EMI Instrument at $30 \mathrm{kHz}$, in $\mathrm{HCP}$ 324 and VCP configurations, and with $0.71 \mathrm{~m}$ and $1.18 \mathrm{~m}$ inter-coil spacings.

325 Figure 3: In-phase response maps after removal of the in-phase part of the conductivity response (CMD, $30 \mathrm{kHz}, \mathrm{HCP}$ and $\mathrm{VCP}, 0.71 \mathrm{~m}$ and $1.18 \mathrm{~m})$ and corresponding magnetic susceptibility scales.

Figure 4: In-phase responses versus relative permittivity and magnetic susceptibility (calculated using $f=30 \mathrm{kHz}, h=0.12 \mathrm{~m}, \sigma=0.1 \mathrm{Sm}^{-1}, \varepsilon_{r}=1000$ for the susceptibility curves, and $\kappa_{p h}=5010^{-5} \mathrm{SI}$ for the permittivity curves).

Figure 5: Apparent magnetic susceptibility and relative permittivity maps derived from HCP and VCP in-phase data.

\section{Table captions}

Table 1: Coefficients of the dependences of the in-phase responses on magnetic susceptibility and relative dielectric permittivity. 


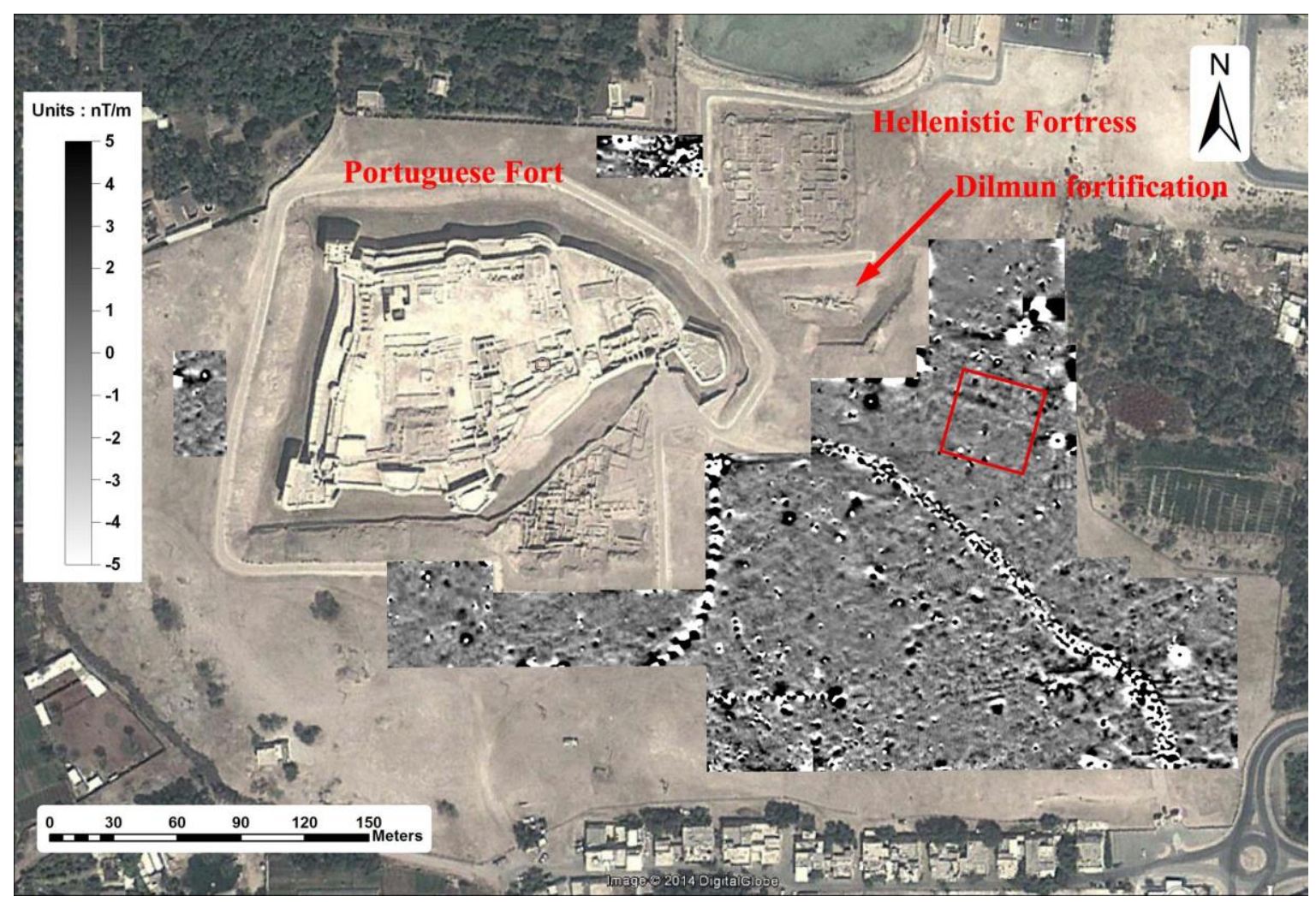

341 Fig. 1a

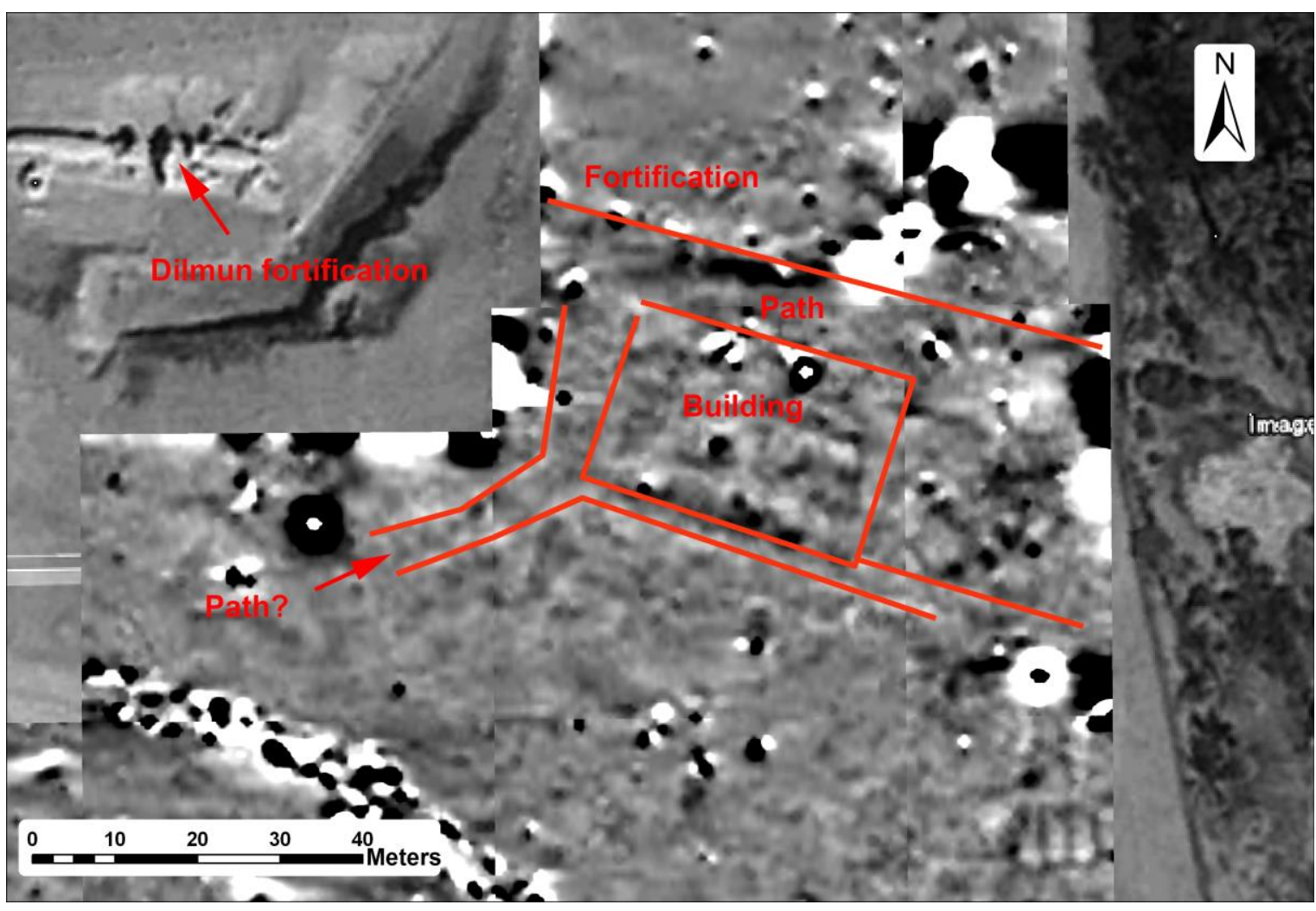

Fig. 1b 
Qalat - al - Bahrain

Apparent résistivity
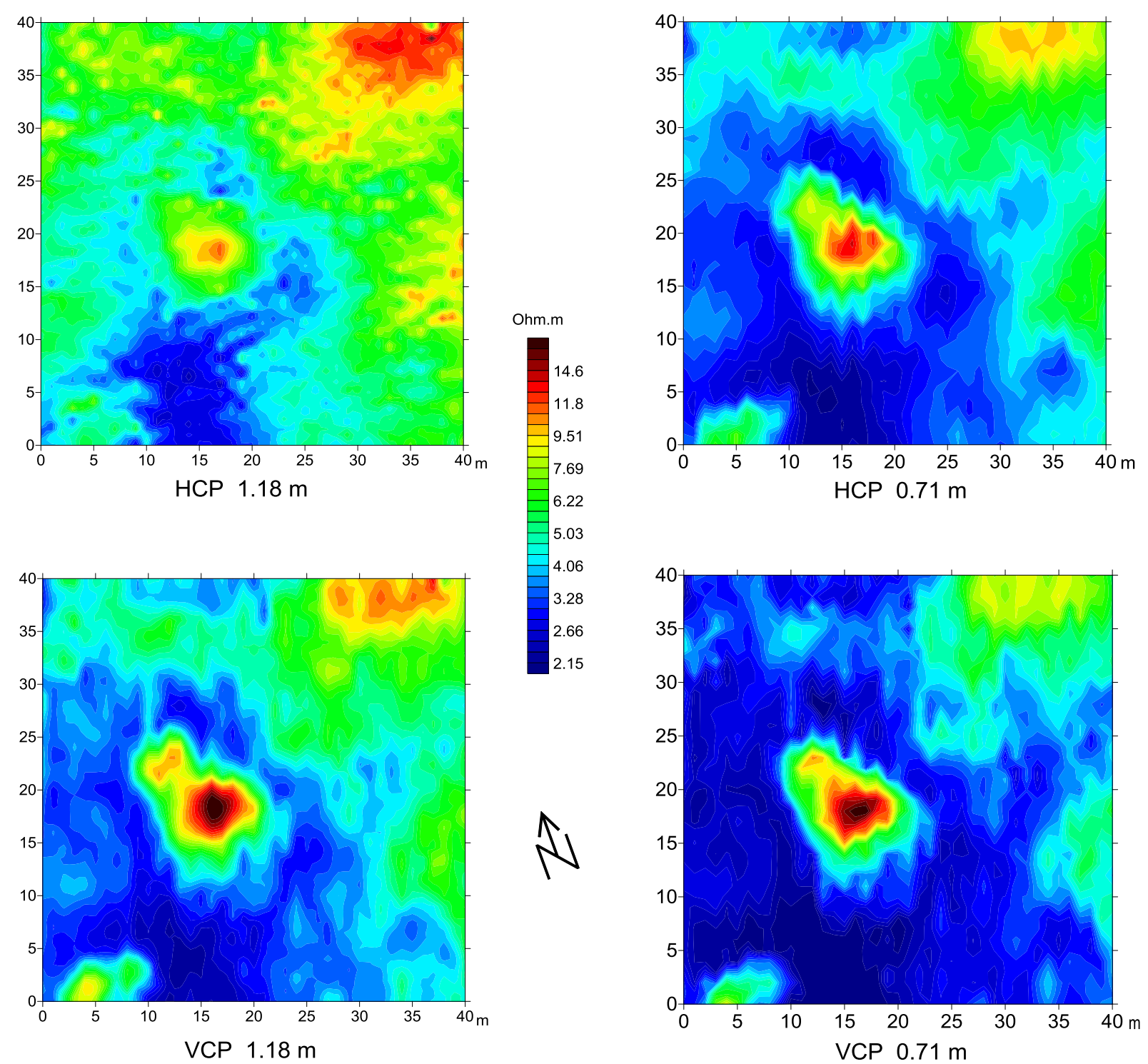

345

Fig.2 
Qalat - al - Bahrain

In-phase respones after removal

of the conductivity responses
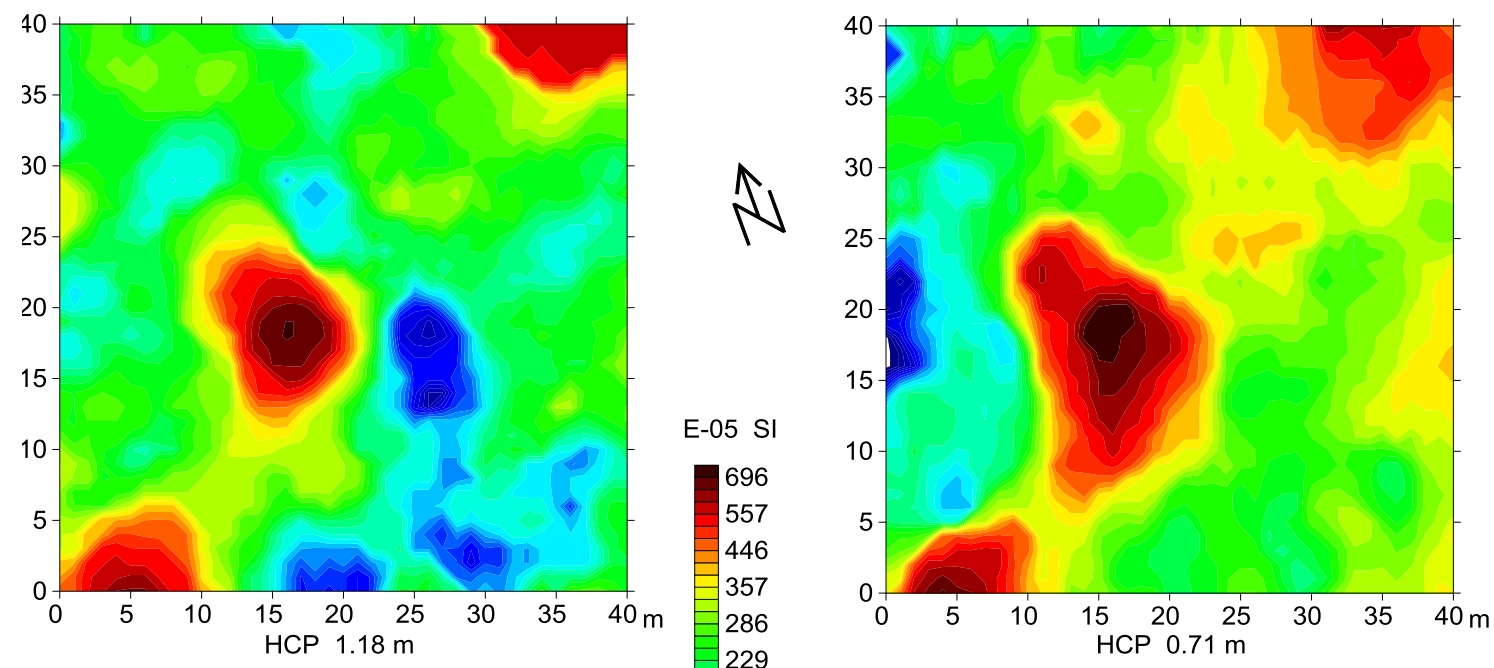

E-05 SI

E-05 SI

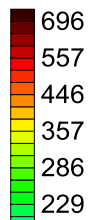

334

268

$\because 214$
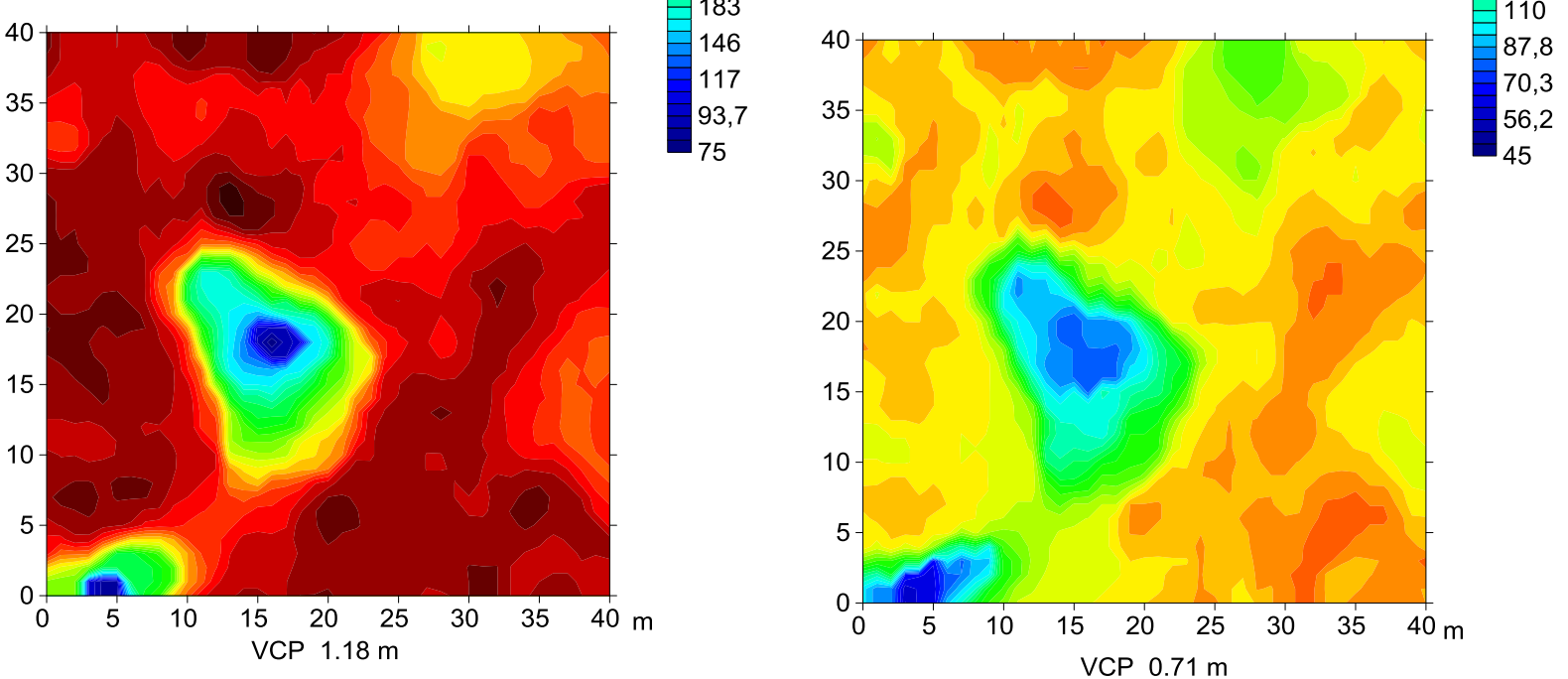

Fig. 3 
352
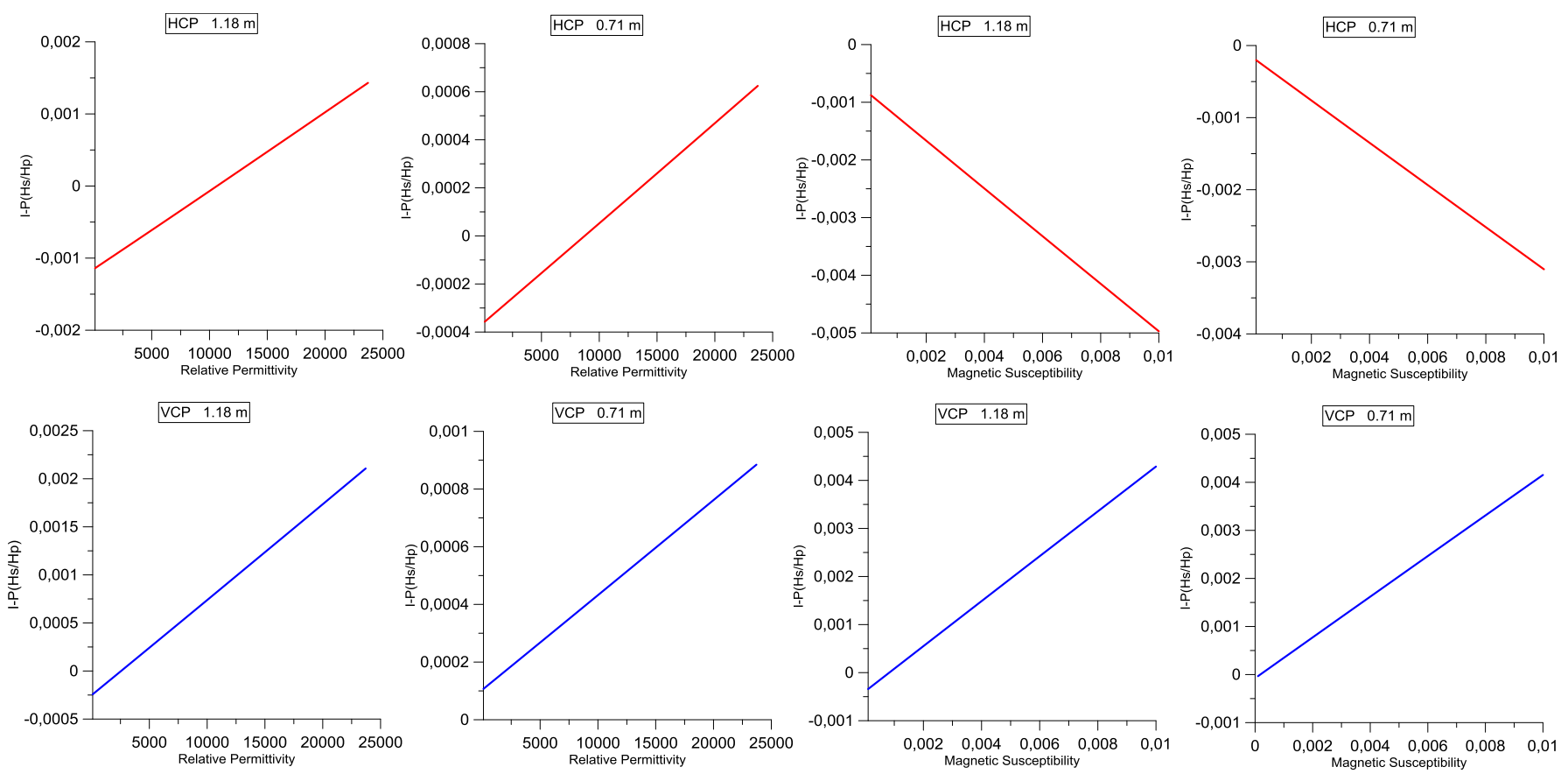

354 Fig. 4 


\section{Qalat - al - Bahrain}
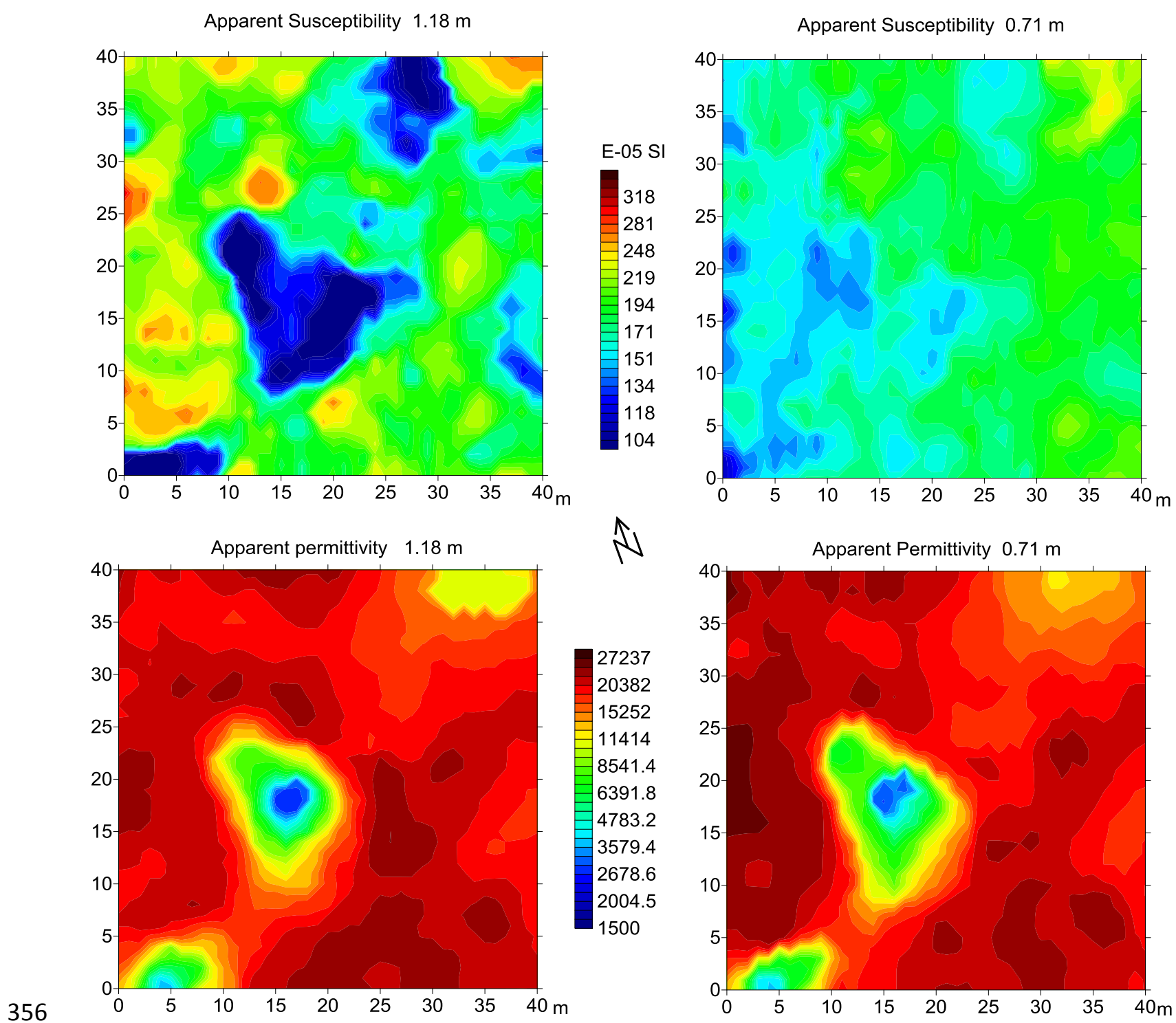

357 Fig. 5 
Table 1

\begin{tabular}{|c|c|c|}
\hline CMD & $\alpha=\frac{\partial P h(H s / H p)}{\partial \kappa_{p h}}$ & $\beta=\frac{\partial P h(H s / H p)}{\partial \varepsilon_{r}}$ \\
$\mathrm{~h}=0.12 \mathrm{~m}, \mathrm{f}=30 \mathrm{kHz}$ & in $\mathrm{ppm} / \mathrm{E}-05 \mathrm{SI}$ & 0.128 \\
\hline $\mathrm{L}=1.18 \mathrm{~m} \mathrm{HCP}$ & -4.15 & 0.109 \\
\hline $\mathrm{L}=1.18 \mathrm{~m} \mathrm{VCP}$ & 4.70 & 0.046 \\
\hline $\mathrm{L}=0.71 \mathrm{~m} \mathrm{HCP}$ & -2.94 & 0.035 \\
\hline $\mathrm{L}=0.71 \mathrm{~m} \mathrm{VCP}$ & 4.25 & \\
\hline
\end{tabular}

361 